\title{
A trindade saramaguiana n'O Evangelho segundo Jesus Cristo
}

\author{
Tânia Mara Antonietti Lopes ${ }^{1}$
}

RESUMO: Com base na figura de Jesus, propomos analisar três personagens - Deus, Diabo e Jesus - em O Evangelho segundo Jesus Cristo (1991), de José Saramago, com o objetivo de apontar a representação de uma curiosa "trindade" estabelecida na obra à medida que o narrador - fio condutor de nossa análise - vai revelando a relação configurada entre Deus e o Diabo num jogo bem articulado, cuja peça principal é Jesus.

ABSTRACT: Based on the figure of Jesus, we propose to analyze the characters God, the Devil and Jesus in O Evangelho Segundo Jesus Cristo (1991), by José Saramago. We aim to point out the configuration of a curious "trinity" established in the work, as narrator - the focal point of our analysis - reveals the relationship between God and the Devil in a well-articulated game, in which the main piece is Jesus.

PALAVRAS-CHAVE: Evangelho; José Saramago; Jesus; Diabo; Narrador

KEYWORDS: Evangelho; José Saramago; Jesus; Devil; Narrator

Ao nos depararmos com o romance ${ }^{2} O$ Evangelho segundo Jesus Cristo, percebemos que as epígrafes são emprestadas da Bíblia e, de certo modo, autorizam José Saramago iniciar a narrativa. A primeira é um fragmento do Evangelho de Lucas:

Já que muitos empreenderam compor uma narração dos factos que entre nós se consumaram, como no-los transmitiram os que desde o principio foram testemunhas oculares e se tornaram servidores da Palavra, resolvi eu também, depois de tudo ter

1 Doutoranda (FCL - UNESP/Araraquara).O realismo mágico e seus diálogos em narrativas de José Saramago. Contato: tma.lopes@yahoo.com.br

2 Este artigo resulta de algumas observações suscitadas na disciplina Imagens de Cristo na Literatura Portuguesa, oferecida pela Profa. Dra. Aparecida de Fátima Bueno (FFLCH-USP), em que tivemos oportunidade de conhecer textos indispensáveis para a averiguação da vertente anticlerical nas obras de autores como Eça de Queirós, Gomes Leal, Guerra Junqueira, Fernando Pessoa e a influência de alguns desses escritores, mesmo que de maneira sutil, n'O Evangelho segundo Jesus Cristo (1991), de José Saramago. 
investigado cuidadosamente desde a origem, expor-tos por escrito e pela sua ordem, ilustre Teófilo, a fim de que reconheças a solidez da doutrina em que foste instruído. (LUCAS, 1, 1-4 apud SARAMAGO, 1999, p.11)

A segunda trata-se da afirmação de Pilatos: "Quod script, script" (SARAMAGO, 1999, p.11). Notamos a consciente escolha que Saramago faz desses versículos para fundamentar sua criação literária, pois se trata de uma ficção capaz de trazer algum desconforto a determinadas crenças "inabaláveis", já que o ateísmo do autor dialoga com o texto bíblico, oficial, com o propósito de subvertê-lo, não para desmistificar a imagem de Jesus, mas para apresentar sua versão humanizadora, sem despi-lo de sua divindade.

A impossibilidade de não invadir os limites da fé se expressa bem na segunda epígrafe, o que revela, do nosso ponto de vista, a percepção do autor português em relação à situação delicada na qual se colocou ao anular, por meio de seu projeto estético, algumas "certezas" do discurso cristão.

O próprio narrador d'O Evangelho segundo Jesus Cristo refere-se ao seu texto como evangelho e se auto-intitula evangelista. Para conceber seu evangelho, esse narrador se desdobra a ponto de se mesclar às vozes das personagens e à linguagem teológica, lançando mão de procedimentos que equilibram perfeitamente descrição, narração e utilização de cenas, fato que muitas vezes o transforma num tipo de deus manipulador e que ao mesmo tempo constrói uma face cruel para Deus.

O narrador desse evangelho poderia ser denominado, de acordo com Gérard Genette (s.d., p.228), predominantemente como extradiegético, pois narra uma história da qual não participa, mas sua onisciência é ilimitada. Quem explica de maneira muito clara a riqueza e variedade de seus procedimentos em relação ao narrador, é o próprio 
Saramago, numa entrevista concedida em 1990 ao Jornal de Letras, Artes e Idéias, na qual o autor sintetiza as nuanças do narrador de Memorial do convento (1982):

Mas há um tipo de narrador, mais complexo, que não tem uma voz única: é um narrador substituível, um narrador que o leitor vai reconhecendo como constante ao longo da narrativa, mas que algumas vezes lhe causará a estranha impressão de ser outro. Digo outro porque ele se colocou num diferente ponto de vista, a partir do qual pode mesmo criticar o ponto de vista do primeiro narrador. $O$ narrador será também, inesperadamente, um narrador que se assume como pessoa coletiva. Será igualmente uma voz que não se sabe de onde vem e que se recusa a dizer quem é, ou usa de uma arte maquiavélica que leve o leitor a sentir-se identificado com ele, a ser, de algum modo, ele. E pode, finalmente, mas de um modo não explícito, ser a voz do próprio autor, capaz de fabricar todos os narradores que entender, não está limitado a saber apenas o que as suas personagens sabem, porquanto ele sabe, e não o esquece nunca, tudo quanto tiver acontecido depois da vida delas.

Tais nuanças estão presentes em toda a produção estética do autor português. É com perfeita destreza que Saramago explicita seus próprios pensamentos fazendo uso de um narrador que constitui em si todos os niveis narrativos apontados por Gérard Genette, possibilitando, dessa forma, variadas focalizações.

De acordo com Oscar Tacca (1983), a visão do narrador determina a perspectiva do romance. No caso de José Saramago, o narrador se manifesta sob múltiplas vozes, e de sua relação de conhecimento com a personagem, o romance extrai a sua maior riqueza. A posição do narrador é importante porque "sempre permanecerá no primeiro plano da audição e da consciência" (TACCA, 1983, p.125), por mais que se diferenciem as vozes.

Concordamos com Maria Célia Leonel (2000) ao aproximar a noção de autor à categoria de autor implícito, proposta por Wayne Booth em The retoric of fiction (1961). Segundo Leonel, a aproximação entre autor e autor implícito só faz sentido se levarmos em conta a instância do narrador, sendo este um dos sujeitos que fala. Dessa 
forma, podemos inferir que "as 'decisões' do narrador podem ser guiadas pelo autor implícito" (LEONEL, 2000, p.69). Assim, é importante ressaltarmos que, tratando-se de José Saramago, por trás dos fatos e da forma retrospectiva como são narrados, há obviamente certa intencionalidade. Por mais que seu narrador esteja próximo da personagem no espaço, está muito mais próximo do autor - no tempo e quanto à opinião sobre os fatos.

Mostrando-se como um ser, embora fictício, dotado de vontade própria, o narrador saramaguiano proporciona o seu próprio desdobramento em vozes que carregam a posição de José Saramago, autor, em relação a Deus. Ao longo do texto, percebemos uma relação de semelhança entre o narrador e Deus, pois o primeiro não quer ser apenas mais um evangelista e sim um demiurgo, revelando o poder de sua onisciência, referindo-se a si próprio na primeira pessoa do plural. Importante em nossas observações é perceber que o narrador concentra toda a sua ironia em Deus, evidenciando sua antipatia por Ele e, por outro lado, demonstra certa predileção pelo Diabo e por Jesus. Um aspecto importante a ressaltar é que o essencial n'O Evangelho segundo Jesus Cristo não é seu final, mas o que o narrador revela da nova trindade: Deus, Diabo e Jesus.

Diferentemente dos quatro Evangelhos canônicos, o de José Saramago terá início com a descrição detalhada da crucifixão de Jesus. É no segundo capítulo do romance que se inicia a sua história. Curiosamente, parece-nos que a trajetória do messias é apresentada na ordem cronológica dos fatos, como no Evangelho de Mateus, mas outros fatos, obscuros no texto bíblico, são acrescentados ou subvertidos no texto saramaguiano.

Notamos, já no início, que o autor apresenta um Jesus humanizado, quase um homem comum se não fossem os milagres que, direta ou indiretamente, opera e alguns fatos misteriosos relacionados a 
ele. Embora Maria e José tenham consumado o ato sexual, a anunciação da concepção é feita supostamente por um anjo.

De acordo com a tradição bíblica, o anjo Gabriel avisou Maria de que ela seria mãe do filho de Deus. No caso deste Evangelho, o aviso é dado por um "anjo" disfarçado de mendigo. Percebemos que não se trata de uma pessoa comum já na maneira como esse encontro é narrado, pois antes de dar início ao diálogo, o narrador nos informa que Maria recebe das mãos do misterioso mendigo uma tigela de barro "a qual, em consequência duma ilusão de óptica em verdade assombrosa, porventura gerada pelas cambiantes luzes do céu, era como se a tivessem transformado em vaso do mais puro ouro [...]" (SARAMAGO, 1999, 32-33).

Percebemos que, desde o início do Evangelho de José Saramago, a aura de mistério se estabelece. O diálogo de Maria com o mendigo/anjo é o primeiro de muitos acontecimentos fabulosos presentes nessa história contada às avessas, como sugere o fragmento a seguir:

Maria segurava a escudela no côncavo das duas mãos [...] como quem esperava que o mendigo lhe depositasse algo dentro, e ele sem explicação assim fez [...] enquanto dizia em surda e ressonante voz, O barro ao barro, o pó ao pó, a terra à terra, nada começa que não tenha de acabar, tudo o que começa nasce do que acabou. Turbou-se Maria e perguntou, Isso que quer dizer, e o mendigo respondeu apenas, Mulher,tens um filho na barriga [...] Como soubeste que estou grávida, Ainda a barriga não cresceu e já os filhos brilham nos olhos das mães [...] E tu quem és, para não teres precisado de ouvi-lo da minha boca, Sou um anjo, mas não o digas a ninguém. (SARAMAGO, 1999, p.33).

O excerto acima nos permite desconfiar do caminho ao qual o narrador nos conduzirá. Já sabemos que o mendigo é um anjo, mas não se trata de Gabriel. O anjo deste Evangelho estará presente por toda a narrativa, do começo ao fim e, como Deus, saberá tudo sobre Jesus, cujo nascimento não tem nada de especial, embora as palavras do narrador sejam ambiguas devido ao tom profético: "O filho de José e de 
Maria nasceu como todos os filhos dos homens, sujo de sangue de sua mãe, viscoso das suas mucosidades e sofrendo em silêncio. Chorou porque o fizeram chorar, e chorará por esse mesmo e único motivo" (SARAMAGO, 1999, p.83).

Repleto de inversões histórico-religiosas, o aparecimento dos três reis magos é um indício de tudo o que acontecerá até o final da narrativa, pois neste episódio os presentes oferecidos a Jesus são diferentes daqueles oferecidos ao menino segundo a tradição. Em vez de ganhar incenso, ouro e mirra, o menino ganhará leite, queijo e pão, presentes terrenos e verdadeiramente úteis a uma família pobre como a de Maria e José. Mas em vez de reis, são pastores que trazem os presentes, e o último deles

[...] num momento pareceu que enchia a cova com sua grande estatura, e disse, mas não olhava nem o pai nem a mãe da criança nascida, Com estas minhas mãos amassei este pão que te trago, com o fogo que só dentro da terra há o cozi. E Maria soube quem ele era. (SARAMAGO, 1999, p.84)

Portanto, o terceiro pastor é o mendigo que anunciou o nascimento de Jesus, e se revela como sendo o próprio Diabo, que daqui para frente será chamado de Pastor. Chegamos, assim, ao que consideramos ser a proposta central de nossa abordagem crítica, ou seja, analisar brevemente as personagens que julgamos essenciais para nossas conclusões: Jesus, Pastor/Diabo e Deus. Assim, não nos deteremos em toda a trajetória de Jesus - seu relacionamento com José, Maria e com seus irmãos, sua vida com Maria de Magdala; passagens essas igualmente merecedoras de estudos mais detalhados mas, especificamente, em dois episódios que consideramos centrais para nossas observações: a experiência de Jesus com o Pastor e os quarenta dias no mar - não no deserto, como preconiza a tradição bíblica -, pois nesses dois episódios Jesus se confronta com Deus e nos é revelada a "verdadeira" relação entre as personagens. 
No Evangelho de Saramago, Jesus é apresentado com um grande senso de justiça. Ao ter conhecimento que José permitiu que Herodes matasse crianças inocentes para ter tempo de salvar apenas seu filho, Jesus decide ir embora de casa, dando início ao encontro com seu destino. Os sentimentos de "abandono, desespero, a solidão infinda de um outro deserto, nem pai, nem mãe, nem irmãos, um caminho de mortos principiado" (SARAMAGO, 1999, p.189), obrigaram Jesus a cumprir o seu destino longe de sua família. "De longe, sentado no meio das ovelhas e confundido com elas, o pastor olhava-o". (SARAMAGO, 1999, p.189)

Notamos que até a metade d'O Evangelho segundo Jesus Cristo Deus não se manifesta. É Pastor quem acompanha, desde o nascimento, a trajetória do messias e será responsável, de certa forma, pela sua formação durante os anos que passa com ele no pastoreio de ovelhas. Jesus carrega consigo a mesma tigela oferecida para Maria.

Evidentemente, o narrador atribui ao Diabo, a tarefa de cuidar de ovelhas. Trata-se, é claro, de uma inversão que promove a simpatia também do leitor por esta personagem, pois é ao lado do Diabo que Jesus aprenderá as coisas realmente importantes, como "as contradições dos sacrificios dos cordeiros, o mistério das obrigações religiosas, a responsabilidade de ter o próprio rebanho, a necessidade dos desejos carnais. O pastor traz-lhe maturidade e prepara-o para a vida adulta". (CALBUCCI, 1999, p.79).

Durante os quatro anos de aprendizagem, Jesus não desconfia que Pastor é o Diabo, embora passe a maior parte do tempo questionando seu comportamento, pois ele não se comporta como um verdadeiro judeu. Numa de suas discussões com Pastor, na qual se questiona o caráter de Deus, Jesus perde a disputa oral:

Escolhe uma ovelha, disse, Quê, perguntou Jesus desnorteado [...] Vais precisar dela, se realmente não és eunuco. [...] Esta é a palavra do Senhor Se um homem se ajuntar com um animal, 
será punido com a morte [...] Ouvide, ouvide, ovelhas que aí estais, ouvide o que nos vem ensinar este sábio rapaz, que não é lícito fornircar-vos, Deus não o permite, podeis estar tranquilas, mas tosquiar-vos, sim, maltratar-vos, sim, matar-vos, sim, e comer-vos, pois para isso vos criou [...]. (SARAMAGO, 1999, p.237-238)

Nesse diálogo, compreendemos que os valores defendidos pelo primeiro vão de encontro àqueles estabelecidos por Deus. Apesar da inversão histórico-religiosa desse evangelho, a vontade de Deus sempre será soberana e é a partir desse momento que sua face será paulatinamente revelada. Por ocasião da Páscoa, Jesus deixa o campo para procurar sua família, levando consigo uma ovelha oferecida pelo pastor. Trata-se, aqui, de um teste de dignidade que consistia na eliminação do ritual sangrento oferecido a Deus.

A princípio, parece-nos que Jesus será bem sucedido no teste, pois na hora suprema do sacrificio do cordeiro, ele decide "contra a lei da sinagoga e a palavra de Deus" (SARAMAGO, 1999, p.250) não matálo e o marca na orelha para distingui-lo dos outros. Mas após três anos desse acontecimento, sua ovelha se desvia para o deserto e, pela primeira vez, Jesus encontra Deus, que exige o sacrifício do animal.

Inevitavelmente, notamos que esse Deus apresentado pelo narrador é um Deus despótico e sarcástico, pois se diverte com a tentativa frustrada de Jesus em salvar a sua ovelha. Nesse momento, observamos que nada escapa aos desígnios de Deus e, aos poucos, verificamos que o narrador nos apresenta um Deus sádico que tenta o próprio filho. Eis a inversão de papéis arquitetada.

No momento em que Jesus cede à exigência de Deus, revela-se o seu papel no evangelho saramaguiano: o de cobaia, pois seu destino pertence a Deus, que manipula os acontecimentos para que Jesus os cumpra; ele não pode, portanto, escolher. A resignação de Jesus diante de Deus provoca certa decepção no Pastor, que ao saber que Jesus cedeu à tentação, dirige-lhe tais palavras: "Não aprendeste nada, vai". (SARAMAGO, 1999, p.265) 
Parece-nos, com base nas palavras de Pastor, que Jesus fora expulso por ele. Curiosamente, percebemos que o narrador concede ao Diabo certa sabedoria, já que ocupa o papel de mestre, enquanto Deus detém o papel de cruel tentador. Por vários momentos, deparamo-nos com diálogos que comprovam a eloquência do Diabo e seu domínio absoluto no manejo das palavras, revelando-se, por meio do autor implícito, sua aversão e a do próprio autor a Deus:

[...] se existe Deus terá de ser um único Senhor, mas era melhor que fossem dois, assim haveria um deus para o lobo e um deus para a ovelha, um para o que morre e outro para o que mata, um deus para o condenado, um deus para o carrasco [...] não gostaria de me ver na pele de um deus que ao mesmo tempo guia a mão do punhal assassino e oferece a garganta que vai ser cortada [...] Não tenho deus, sou como uma de minhas ovelhas [...]. (SARAMAGO, 1999, p.233)

N'O Evangelho segundo Jesus Cristo chegamos à conclusão de que o Diabo será mais importante do que o próprio messias. A partir do momento em que Jesus se vê sozinho novamente, inicia-se outra caminhada, na qual ele sempre questionará com angústia a sua condição de "filho de Deus". Até o seu segundo e definitivo encontro com Ele, Jesus passará a sua maturidade ao lado de Maria de Magdala. Ambos viverão junto a pescadores, para os quais Jesus operará milagres.

O que nos interessa, contudo, para esta análise, é o encontro entre Jesus e Deus, e dessa vez também com o Diabo, não no deserto, mas no meio do mar. Esse encontro é fundamental para que entendamos o papel de cada um deles na construção do evangelho saramaguiano.

O clímax da narrativa ocorre na barca onde Jesus se encontra e em meio a um estranho nevoeiro. O diálogo levará quarenta dias, nos quais fatos reveladores serão esclarecidos, teremos a confirmação de que Jesus não fora concebido por uma virgem, já que Deus misturara sua semente com a de José; nesse caso, esse amálgama, ou seja, a 
junção do divino com o humano, talvez explique a natureza ambígua (humana e divina) do messias saramaguiano. Também se esclarece a relação do Pastor/Diabo com Deus, intensificada pelo narrador. A princípio, o Diabo parece ser aliado de Deus, mas no decorrer dos diálogos, fica claro que não é de seu interesse tomar o partido do Onipotente.

A Jesus é revelado seu destino: nas palavras de Deus, seu filho será a colher que Ele mergulhará na humanidade "para a retirar cheia dos homens que acreditarão no deus novo" no qual tornar-se-á. (SARAMAGO, 1999, p.372). Em sua crueldade, Deus revela a Jesus o que o cristianismo trará ao mundo e o filho de Deus tenta desesperadamente e sem sucesso mudar o seu destino, pois não quer ser o motivo de todo o sofrimento por qual passará a humanidade.

O próprio Diabo se compadece de Jesus e tenta um acordo com Deus, e nesse momento percebemos que se concretiza uma nova trindade, ou seja, a união inevitável das três personagens. Essa união é necessária para que se cumpram os desígnios do Senhor. O acordo proposto pelo Diabo é que Deus o perdoe e o aceite novamente no céu como seu humilde filho, ao que Deus responde:

Não te aceito, não te perdôo, quero-te como és, e, se possível, ainda pior do que és agora, Porquê, Porque este Bem que eu sou não existiria sem esse Mal que tu és, [...] se tu acabas, eu acabo, para que eu seja o Bem, é necessário que tu continues a ser o $\mathrm{Mal}$, se o Diabo não vive como o Diabo, Deus não vive como Deus, a morte de um seria a morte do outro [...] (SARAMAGO, 1999, p. 343)

Deus não poderia aceitar tal oferta, ou teria transformado o Diabo no salvador da humanidade. O fragmento acima confirma o perfeito funcionamento da trindade Jesus-Diabo-Deus, pois é a partir dessa união que o cristianismo faz sentido. Nesse aspecto, nossa análise vai ao encontro do trabalho de Salma Ferraz (2003), que também interpreta a relação das três personagens como uma nova trindade, "complexa" e "estranha”. (p.189) Jesus tenta, mas não consegue frustrar o plano de 
Deus. A partir desse encontro, todos os caminhos o levarão ao seu destino. No momento da agonia de Cristo na cruz

[...] Deus aparece [...] e a sua voz ressoa por toda a terra, Tu és o meu filho muito amado, em ti pus a minha complacência, Então Jesus compreendeu que viera trazido ao engano [...], que a sua vida fora traçada para morrer assim desde o princípio dos princípios [...] (SARAMAGO, 1999, p.444)

Com base em algumas reflexões sobre $O$ Evangelho segundo Jesus Cristo, acreditamos que o autor implícito, disfarçado com a voz de um narrador tão astuto quanto o Diabo e até mais onisciente que o próprio Deus, inevitavelmente expressa as idéias do próprio autor.

Considerando a nova trindade estabelecida por ele, em seu evangelho, notamos que ela é necessária para o funcionamento do cristianismo. Dessa forma, podemos inferir que a postura anti-cristã e anti-religiosa de José Saramago não é mais incômoda do que a postura de outros escritores portugueses do século XIX, cujo ataque era tão direto e, muitas vezes, até mais veemente do que o que ocorre no romance de Saramago. Parece-nos, assim, que o mais importante n'O Evangelho segundo Jesus Cristo é tornar explícita a face de Deus, ou seja, mostrar que o principal responsável por todas as misérias do mundo é Ele. Eis as prováveis intenções do narrador saramaguiano: apresentar uma trindade arquitetada pelo próprio Criador. A história oficial da Bíblia é subvertida para revelar um Deus cruel. Em nenhum momento se questionam os milagres de Jesus ou seu papel no universo. O seu papel de mártir se confirma e sua divindade, mesmo que paradoxal, se mantém.

\section{Referências Bibliográficas:}

CALBUCCI. Eduardo. Saramago: um roteiro para os romances. São Paulo: Ateliê Editorial, 1999. 
FERRAZ, Salma. As faces de Deus na obra de um ateu. Juiz de Fora: Blumenau:Edifurb, 2003.

GENETTE, Gérard. Discurso da Narrativa. Tradução de Fernando Cabral Martins.Lisboa: Vega, s.d.

LEONEL, Maria Célia. Os sujeitos que falam: escritor, autor, autorimplícito, narrador. In: Guimarães Rosa: Magma e gênese da obra. São Paulo: Unesp, 2000, p.67-75.

SARAMAGO, José. O Evangelho segundo Jesus Cristo. São Paulo: Companhia das Letras, 1999.

Jornal de Letras, Artes e Idéias, 1990. In: CORRÊA, Silvana Aparecida Domingos. A História tecida e destecida em I Promessi Sposi $e$ Memorial do convento. 2003. 120 f. Dissertação de Mestrado. IBILCE Unesp, São José do Rio Preto, 2003.

TACCA, Oscar. As vozes do romance. Trad. Margarida Coutinho Gouveia. 2. ed.Coimbra: Livraria Almedina, 1983. 